\title{
TRIB1 rs17321515 and rs2954029 gene polymorphisms increase the risk of non- alcoholic fatty liver disease in Chinese Han population
}

\author{
Qun Liu ${ }^{1,3}$, Feng Xue 2 , Jing Meng ${ }^{2}$, Shou-Sheng Liu ${ }^{4,5}$, Li-Zhen Chen ${ }^{2}$, Hui Gao ${ }^{1,3}$, Ning Geng ${ }^{2}$, Wen-Wen Jin ${ }^{2}$, \\ Yong-Ning $X_{i n}^{1,2,3,5^{*}}$ (i) and Shi-Ying Xuan ${ }^{1,3,5^{*}}$
}

\begin{abstract}
Background: Dysregulation of the lipid homeostasis is an independent risk factor for non-alcoholic fatty liver disease (NAFLD). Some studies had demonstrated that TRIB1 gene polymorphisms affect the plasma lipids metabolism, but no related data was available for TRIB1 gene polymorphisms in the lipids metabolism in Chinses Han population. The present study was conducted to investigate the association between TRIB1 gene polymorphisms (rs17321515 and rs2954029) and the risk of NAFLD in Chinese Han population and their effects on serum lipid profiles.

Patients and methods: TRIB1 rs17321515 and rs2954029 gene polymorphisms were genotyped using the polymerase chain reaction (PCR) in B-type ultrasonography-proven NAFLD patients $(n=146)$ and healthy controls $(n=175)$. Serum lipid profiles were determined using biochemical methods. Statistical analyses were performed using SPSS 22.0 statistical software.

Results: The allele distributions of TRIB1 rs17321515 A and rs2954029 A were significant different between the NAFLD patients and healthy controls $(P=0.026, P=0.045$, respectively). The genotype distribution of TRIB1 rs 17321515 was significant different between NAFLD patients and healthy controls $(P=0.038)$. The TRIB1 rs17321515 GA + AA genotype and TRIB1 rs2954029 TA + AA genotype markedly increase the NAFLD risk (OR=1.885; 95\%Cl: 1.157-3.070; $\mathrm{OR}=1.627$; 95\%Cl: 1.011-2.619, respectively), after adjusted for age, gender, and body mass index, the NAFLD risk still significant (OR $=2.240 ; 95 \% \mathrm{Cl}$ : 1.196-4.197; OR=2.050; 95\%Cl: 1.110-3.786, respectively). In addition, TRIB1 rs17321515 A and rs2954029 A carriers possess the higher lipid profiles in the included subjects.
\end{abstract}

Conclusions: TRIB1 rs17321515 and rs2954029 were significant associated with the risk of NAFLD in Chinese Han population. The rs17321515 A and rs2954029 A allele increases the serum lipid profiles in Chinese Han population.

Keywords: Non-alcoholic fatty liver disease, TRIB1, Polymorphism, lipids metabolism

\section{Background}

Non-alcoholic fatty liver disease (NAFLD), the most common form of chronic liver diseases, is now recognized as a severe public health concern in the worldwide [1]. The overall prevalence of NAFLD is approximately 25 and $27 \%$ in the world and Asian, respectively [2, 3]. Established risk factors for NAFLD including aging, insulin resistance, hyperlipidemia, obesity, type 2 diabetes,

\footnotetext{
* Correspondence: xinyongning@163.com; xuansydxy@163.com

${ }^{1}$ Medical College of Qingdao University, Qingdao 266071, China Full list of author information is available at the end of the article
}

dysregulation of the lipid homeostasis, and genetic factors, and the prevalence of NAFLD is increased with the increasing body mass index [4-8]. Biopsy is still regarded as the diagnostic gold standard for NAFLD, but the deficiency of biopsy such as invasiveness and possible sample error remain could be ignored $[9,10]$. In recent years, some non-invasive, genetics-based clinical diagnostic methods for NAFLD had been developed. Leon-Mimila et al. reported a genetic risk score system that could evaluate the risk of NASH by combining the variant alleles of PNPLA3 rs738409, LYPLAL1 
rs12137855, GCKR rs1260326, and PPP1R3B rs4240624 [11]. Accumulated studies emphasized that finding the new SNPs site which associated with NAFLD is very meaningful for the prediction and diagnosis of NAFLD.

Tribbles-1 (TRIB1) is one of the members of tribbles family that was first identified in Drosophila and possesses the function to regulate the cell division and migration [12, 13]. In 2008, genome-wide association studies (GWAS) first revealed the association of TRIB1 rs17321515 (A > G) and rs2954029 (A > T) gene polymorphisms with the serum level of triglycerides (TG) $[14,15]$. Subsequent abundant studies had shown that TRIB1 rs17321515 and rs2954029 were significant associated with the dysregulation of serum lipids levels and the risk of cardiovascular disease. Tai et al. investigated the effect of TRIB1 rs17321515 in Malay population, the results showed that TRIB1 rs17321515 was significant associated with the elevated level of total cholesterol (TC) and low density lipoprotein (LDL), and the risk of cardiovascular disease (CVD) [16]. The elevated serum TG level and risk of coronary heart disease in TRIB1 rs17321515 A allele carriers in Chinese Han population were also be observed [17]. Varbo et al. conducted a study to test the effect of TRIB1 rs2954029 in the general population, the results showed that TRIB1 rs2954029 A allele carriers had the higher serum levels of TG, TC, apolipoprotein $\mathrm{B}$, and LDL-C, and the lower high density lipoprotein (HDL) than A allele non-carriers [18]. The similar effect of TRIB1 rs2954029 in lipids metabolism was also observed in Japanese community-dwelling women, which showed an elevated TG concentration in AA genotype carriers [19].

There is no doubt about the significant role of TRIB1 rs17321515 and rs2954029 in the lipid metabolism and the risk of cardiovascular disease. In consideration of the tight association of NAFLD with the dysregulation of lipids metabolism and the risk of cardiovascular disease [20-22], it is meaningful to explore the effect of TRIB1 rs17321515 and rs2954029 in the NAFLD patients. The purpose of this study was to investigate the association of TRIB1 rs17321515 and rs2954029 with the risk of NAFLD and their effects on the lipid metabolism in Chinese Han population.

\section{Patients and methods}

\section{Study subjects}

This case-control study was approved by the Ethical Committee of Qingdao Municipal Hospital (Qingdao, China). This study was carried out in accordance with the principles of the declaration of Helsinki and its appendices [23]. All the subjects had written the informed consent before participated in this study.

From June 2018 to November 2018, 146 NAFLD patients diagnosed by B-type ultrasonography ( 65 females and 81 males, mean age $61.08 \pm 15.70$ years) and 175 B-type ultrasonography confirmed healthy controls that matched for sex and age ( 87 females and 88 males, mean age $60.15 \pm 11.96$ years) were enrolled in this study. The NAFLD patients were collected from the Department of Gastroenterology and the healthy controls were collected from the Medical Center of Qingdao Municipal Hospital. All the individuals were unrelated Northern Han Chinese origin. The diagnosis of NAFLD was performed according to the guidelines of American association for the study of liver diseases (AASLD) [24]. Subjects with other causes of liver disease were excluded, including excess alcohol intake ( $\geq 210 \mathrm{~g} /$ week for males and $\geq 140 \mathrm{~g} /$ week for females), chronic viral hepatitis, drug-induced liver injury, Wilson's disease, alphal-antitrypsin deficiency, viral and autoimmune hepatitis, alphal-antitrypsin deficiency and alpha-l-antitrypsin deficiency. The healthy controls were confirmed by the same examination at Qingdao Municipal hospital.

\section{Biochemical analyses}

The basic clinical information (name, gender, age, body height, and weight) were obtained by a standard study questionnaire. The body mass index (BMI) of each subject was calculated equals to mass $(\mathrm{kg}) /$ height $(\mathrm{m})^{2}$. Blood sample was collected from median vein of each subject after a 12-h overnight, and the blood sample was placed into an ethylene diamine tetraacetic acid (EDTA)-containing tube. The serum levels of alanine aminotransferase (ALT), aspartate aminotransferase (AST), gamma-glutamyltranspeptidase (GGT), alkaline phosphatase (ALP), triglyceride (TG), total cholesterol (TC), high-density lipoprotein (HDL), low-density lipoprotein (LDL), total bilirubin (TBIL), fasting plasma glucose (FPG) were measured by standard clinical laboratory techniques (IChem-540 automatic biochemical analyzer, Shenzhen, China), respectively. Environmental factors were excluded in the study.

\section{Genomic DNA extraction and genotyping}

Blood genomic DNA was isolated with a genomic DNA purification kit (TIANGEN, Beijing, China) according to the manufacturer's instructions and stored at $-20^{\circ} \mathrm{C}$ until use. The genotyping of 2 SNPs, rs17321515 and rs2954029, in the TRIB1 gene was conducted using the polymerase chain reaction (PCR). Primers for PCR were 5' - ACGTTGGATGTAGAAGTCCCCTTCCCTTAG -3' and 5' - ACGTTGGATGGAACAAGGACTTTCGTCCT C-3'(reverse) for rs17321515, 5' - ACGTTGGATGAC GAGCTTTGTGTCATGAGG- 3', and 5' - ACGTTGG ATGAGCTGCTGATGGTATTTTAC-3' for rs2954029. PCR amplification was performed under the following conditions: an initial denaturation at $94{ }^{\circ} \mathrm{C}$ for $5 \mathrm{~min}$, followed by 45 cycles of denaturing at $94^{\circ} \mathrm{C}$ for $20 \mathrm{~s}$, annealing at $56{ }^{\circ} \mathrm{C}$ for $30 \mathrm{~s}$, and extending at $72{ }^{\circ} \mathrm{C}$ for 1 
min. The genotypes of rs17321515 and rs2954029 were detected by direct DNA sequencing using the ABI veriti-384 Prism sequence detection system, and the raw data were analyzed using MassARRAY TYPER4.0 software (Agena, Inc). Genotyping was performed in blinded fashion and the success rates were $>95 \%$.

\section{Statistical analysis}

Statistical analysis was carried out using the statistical package for the social sciences (SPSS), version 22.0 (SPSS Inc. Chicago, IL, USA). The Hardy-Weinberg equilibrium between expected and observed genotype distribution and the distributions of genotype between patients and controls were analyzed by Pearson's $X^{2}$ test. Baseline characteristics of each subjects were tested by $t$ test and reported as mean \pm standard deviation (S.D.). The Genotypes and allele frequencies were evaluated using the $X^{2}$ test, and the distributions between the NAFLD patients and the healthy controls were analyzed using the Fisher exact test or the Pearson $X^{2}$ test, where appropriate. The association between SNP and NAFLD risk was estimated by computing odds ratios (ORs) and 95\% confidence intervals $(\mathrm{CI})$ from the multivariate logistic regression analyses. $P<0.05$ was considered as statistically significant.

\section{Results}

\section{Clinical characteristics of the study population}

The clinical characteristics of NAFLD patients and healthy controls are shown in the Table 1 . The two groups were matched for gender and age (both $P>0.05$ ). The NAFLD patients had higher BMI value and serum levels of ALT, GGT, TG, TC, LDL and FPG than healthy controls (all $P<0.05$ ), besides, the serum level of HDL in NAFLD patients was significant low compared to the healthy controls $(P<0.05)$, No significant differences of serum AST, ALP, TBIL levels were observed between NAFLD patients and healthy controls (all $P>0.05$ ).

\section{Genotype and allele distribution of TRIB1 rs17321515 and rs2954029}

The genotype distributions of TRIB1 rs17321515 and rs2954029 were in accordance with the Hardy-Weinberg equilibrium in both the NAFLD patients and healthy controls (all $P>0.05$ ) (Table 2). As described in the Table 3, there were significant differences in the genotypes and alleles distribution of TRIB1 rs17321515 between NAFLD patients and controls group $(P=0.038$; $P=0.026$, respectively). The TRIB1 rs17321515 GA + AA genotype was the significant risk factor for the development of NAFLD (OR $=1.885 ; 95 \% \mathrm{CI}$ : 1.157-3.070; $P=$ 0.010), after adjusted for age, gender, and body mass index, the risk of TRIB1 rs17321515 GA + AA genotype was still marked $(\mathrm{OR}=2.240 ; 95 \% \mathrm{CI}$ : 1.196-4.197; $P=$
Table 1 Clinical Characteristics of Patients with NAFLD and Healthy Controls ${ }^{a}$

\begin{tabular}{llll}
\hline & NAFLD patients $(n=146)$ & Controls $(n=175)$ & $P$ Value \\
\hline Female (\%) & $65(44.52)$ & $87(49.71)$ & 0.353 \\
Age $(\mathrm{y})$ & $61.08 \pm 15.70$ & $60.15 \pm 11.96$ & 0.561 \\
BMI $\left(\mathrm{kg} / \mathrm{m}^{2}\right)$ & $26.93 \pm 3.85$ & $22.44 \pm 2.88$ & $<0.001$ \\
ALT $(\mathrm{U} / \mathrm{L})$ & $29.95 \pm 17.69$ & $22.21 \pm 20.63$ & $<0.001$ \\
AST $(\mathrm{U} / \mathrm{L})$ & $24.22 \pm 9.01$ & $22.88 \pm 13.03$ & 0.299 \\
GGT $(\mathrm{U} / \mathrm{L})$ & $39.56 \pm 26.48$ & $29.57 \pm 36.35$ & 0.006 \\
ALP $(\mathrm{U} / \mathrm{L})$ & $70.99 \pm 16.69$ & $73.75 \pm 24.39$ & 0.234 \\
TG $(\mathrm{mmol} / \mathrm{L})$ & $1.92 \pm 1.31$ & $1.33 \pm 0.76$ & $<0.001$ \\
TC $(\mathrm{mmol} / \mathrm{L})$ & $5.47 \pm 0.82$ & $4.24 \pm 1.39$ & $<0.001$ \\
HDL $(\mathrm{mmol} / \mathrm{L})$ & $1.20 \pm 0.22$ & $1.30 \pm 0.37$ & 0.001 \\
LDL (mmol/L) & $3.28 \pm 0.53$ & $3.11 \pm 0.70$ & 0.012 \\
TBIL (umol/L) & $13.15 \pm 4.67$ & $13.11 \pm 5.18$ & 0.942 \\
FPG (mmol/L) & $5.62 \pm 1.93$ & $4.63 \pm 0.84$ & $<0.001$ \\
\hline Abbrevions: BMI & body mass &
\end{tabular}

Abbreviations: $B M I$ body mass index, $A L T$ alanine aminotransferase, $A S T$ aspartate aminotransferase, GGT $\gamma$-glutamyltransferase, $A L P$ alkaline phosphatase, $T G$ triglyceride, $T C$ total cholesterol, $H D L$ high-density lipoprotein, LDL low-density lipoprotein, TBIL total bilirubin, FPG fasting plasma glucose, NAFLD nonalcoholic fatty liver disease

${ }^{a}$ Values are expressed as mean \pm SD and compared by Student's t-test

0.012) (Table 4). There was no significant difference in the genotype distribution of TRIB1 rs2954029, between NAFLD patients and controls group $(P=0.076)$, but a noteworthy difference of TRIB1 rs2954029 allele distribution was observed between NAFLD patients and controls group $(P=0.045)$ (Table 3$)$. The TRIB1 rs2954029 $\mathrm{TA}+\mathrm{AA}$ genotype was the significant risk factor for the development of NAFLD (OR $=1.627$; 95\%CI: $1.011-$ 2.619; $P=0.045)$, after adjusted for age, gender, and body mass index, the risk of TRIB1 rs2954029 TA + AA genotype was still significant $(\mathrm{OR}=2.050 ; 95 \% \mathrm{CI}: 1.110-$ 3.786; $P=0.022$ ) (Table 4).

\section{Association of the TRIB1 polymorphisms with clinical parameters in each group subjects}

To investigate the potential correlation of TRIB1 polymorphisms with the clinical parameters in each study group, we compared the TRIB1 rs17321515 A allele and TRIB1 rs2953029 A allele with the clinical parameters of the overall series subjects, NAFLD patients and healthy controls. As shown in the Table 5, TRIB1 A allele

Table 2 Results of the Hardy-Weinberg Equilibrium ${ }^{\text {a }}$

\begin{tabular}{llll}
\hline Gene Locus & Groups & $X^{2}$ & $P$ Value \\
\hline rs17321515 & NAFLD patients & 0.403 & 0.526 \\
& Controls & 1.693 & 0.193 \\
rs2954029 & NAFLD patients & 0.041 & 0.840 \\
& Controls & 2.905 & 0.088 \\
\hline
\end{tabular}

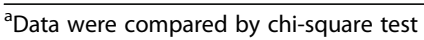


Table 3 Distribution of Genotypes and Allele Frequencies of TRIB1 in NAFLD Patients and Controls ${ }^{\mathrm{a}, \mathrm{b}}$

\begin{tabular}{cllll}
\hline & NAFLD patients & Controls & $x^{2}$ & P Value \\
\hline $\begin{array}{c}\text { rs17321515 } \\
\text { Genotypes }\end{array}$ & & & & \\
GG & $37(26.6)$ & $67(40.6)$ & & \\
GA & $73(52.5)$ & $70(42.4)$ & & \\
AA & $29(20.9)$ & $28(17.0)$ & & \\
Alleles & & & 4.942 & 0.026 \\
G & $147(52.9)$ & $204(61.8)$ & & \\
A & $131(47.1)$ & $126(38.2)$ & & \\
rs2954029 & & & & \\
Genotypes & & & & \\
TT & $40(27.4)$ & $69(39.4)$ & & \\
TA & $74(50.7)$ & $73(41.7)$ & & \\
AA & $32(21.9)$ & $33(18.9)$ & & \\
Alleles & & & 4.076 \\
T & $152(52.4)$ & $211(60.3)$ & & \\
A & $138(47.6)$ & $139(39.7)$ & & \\
\hline
\end{tabular}

${ }^{a}$ Data were compared by chi-square test

b Values are expressed as No. (\%)

carriers had the higher serum levels of GGT, TG, TC and LDL than non-carriers in the overall series (all $P$ $<0.05$ ). The higher serum level of LDL in the A allele carriers compared to the non-carriers in the NAFLD patients was observed $(P<0.05)$. In the healthy controls, the A allele carriers also had the higher serum TC level than non-carriers $(P<0.05)$. For the TRIB1 rs2953029, there were higher serum levels of GGT and LDL in the A allele carriers than non-carriers in the overall series (both $\mathrm{P}<0.05$ ), and the serum level of $\mathrm{TC}$ in the $\mathrm{A}$ allele carriers was significant high compared to the non-carriers in the healthy controls $(P<0.05)$ (Table 6).

\section{Discussion}

NAFLD is one of the most prevalent chronic liver diseases in the world and causes related morbidity and

Table 4 Association of Genotypes with NAFLD in the Study Group $^{a}$

\begin{tabular}{lllll}
\hline Unadjusted & & & Adjusted $^{\text {a }}$ & \\
\cline { 2 - 3 }$(95 \% \mathrm{Cl})$ & $P$ Value & & OR $(95 \% \mathrm{Cl})$ & $P$ Value
\end{tabular}

rs17321515

$\begin{array}{lllll}\text { GG } & 1 & 1 & \\ \text { GA + AA } & 1.885(1.157-3.070) & 0.010 & 2.240(1.196-4.197) & 0.012 \\ \text { I } 2954029 & & & & \\ \Pi & 1 & 1 & \\ \text { TA + AA } & 1.627(1.011-2.619) & 0.045 & 2.050(1.110-3.786) & 0.022\end{array}$

${ }^{a}$ Binary logistic regression model was adjusted for age, gender, and body mass index mortality of HCC [25]. NAFLD is a complicated manifestation of metabolic syndrome which characterized with obesity, insulin resistant, type 2 diabetes mellitus, hyperlipidemia, the risk of NAFLD development is significant associated with the environmental factors and genetic factors and so on [26-28]. Single nucleotide polymorphism (SNP) as a significant genetic factor, plays an important role in the development of NAFLD [29]. Many variants in PNPLA3, TM6SF2, MBOAT7, GCKR and so on which are significant associated with the risk of NAFLD had been found by genome-wide association studies [30]. In this study, we investigated the relationship of TRIB1 rs17321515 and rs2954029 gene polymorphisms with the risk of NAFLD in the Chinese Han population for the first time. We found that TRIB1 rs17321515 A and rs2954029 A alleles were significantly associated with the risk of development of NAFLD, and the genotype distribution of TRIB1 rs17321515 was significant different between NAFLD patients and healthy controls.

Tribbles-1 (TRIB1) is one of the member of tribbles family that was first identified in Drosophila and possesses the function to regulate the cell division and migration [12, 13], subsequent studies confirmed that TRIB1 encodes a human homologue of the Drosophila tribbles protein and the association of TRIB1 variant with the serum lipids metabolism was discovered by GWAS in the European population [14,31]. In view of the new role of TRIB1 in lipoprotein metabolism, Burkhardt et al. investigated the role of hepatic TRIB1 on the serum lipoproteins in mice, they found the serum levels of TG and cholesterol were significant variational in the TRIB1-knockout mice or mice with TRIB1 hepatic-specific overexpression [32]. Accumulated evidences had been reported which focus on the significant role of TRIB1 rs17321515 and rs2954029 in the development of NAFLD in different ethnic groups. In a Spanish familial hypercholesterolemia cohort study, the higher waist circumference and higher serum TG level were observed in the rs1732151 A/A carriers [33]. In a 10-year follow-up of the GLACIER study, Varga et al. reported that TRIB1 rs2954029 was strongly associated with the 10-year changes in lipid levels [34]. In consideration of deficient data of TRIB1 rs17321515 and rs2954029 in the lipids metabolism in Chinese Han population, we investigated the relationship of TRIB1 rs17321515 and rs2954029 with the risk of NAFLD and their effects on lipid profiles in Chinese Han population. We observed that TRIB1 rs17321515 A and rs2954029 A alleles were significantly associated with the development risk of NAFLD, and the genotype distribution of rs17321515 was markedly different between NAFLD patients and healthy controls. In addition, rs17321515 A carriers possess the higher serum levels of GGT, TG, TC, and LDL 
Table 5 Clinical Characteristics of TRIB1 rs17321515 A Carriers and Non-Carriers in the Study Population ${ }^{a}$

\begin{tabular}{|c|c|c|c|c|c|c|c|c|c|}
\hline \multirow[t]{2}{*}{ Characteristic } & \multicolumn{3}{|l|}{ Overall Series } & \multicolumn{3}{|c|}{ NAFLD Patients } & \multicolumn{3}{|l|}{ Controls } \\
\hline & $\begin{array}{l}\text { Carriers } \\
(n=200)\end{array}$ & $\begin{array}{l}\text { Non-Carriers } \\
(n=104)\end{array}$ & $P$ Value & $\begin{array}{l}\text { Carriers } \\
(n=102)\end{array}$ & $\begin{array}{l}\text { Non-Carriers } \\
(n=37)\end{array}$ & $P$ Value & $\begin{array}{l}\text { Carriers } \\
(n=98)\end{array}$ & $\begin{array}{l}\text { Non-Carriers } \\
(n=67)\end{array}$ & $P$ Value \\
\hline Female, \% & $94(47.0)$ & $50(48.1)$ & 0.858 & $48(47.1)$ & $17(45.9)$ & 0.907 & $46(46.9)$ & $33(49.3)$ & 0.770 \\
\hline Age, y & $60.40 \pm 13.96$ & $60.82 \pm 13.73$ & 0.801 & $60.37 \pm 15.53$ & $62.83 \pm 16.14$ & 0.399 & $60.42 \pm 12.18$ & $59.76 \pm 12.29$ & 0.735 \\
\hline $\mathrm{BMl}, \mathrm{kg} / \mathrm{m}^{2}$ & $24.68 \pm 4.29$ & $24.12 \pm 3.57$ & 0.255 & $27.01 \pm 4.19$ & $26.73 \pm 2.86$ & 0.702 & $22.27 \pm 2.81$ & $22.66 \pm 3.02$ & 0.397 \\
\hline$A L T, U / L$ & $27.27 \pm 22.09$ & $23.65 \pm 14.97$ & 0.093 & $30.23 \pm 17.19$ & $29.25 \pm 19.07$ & 0.766 & $24.18 \pm 25.97$ & $19.92 \pm 9.90$ & 0.143 \\
\hline AST, U/L & $23.74 \pm 11.88$ & $23.19 \pm 11.11$ & 0.691 & $24.26 \pm 8.57$ & $24.12 \pm 10.14$ & 0.937 & $23.21 \pm 14.57$ & $22.50 \pm 11.40$ & 0.736 \\
\hline GGT, U/L & $36.88 \pm 37.78$ & $29.70 \pm 20.29$ & 0.032 & $40.72 \pm 26.74$ & $36.68 \pm 25.92$ & 0.411 & $32.88 \pm 46.39$ & $25.70 \pm 15.16$ & 0.156 \\
\hline$A L P, U / L$ & $72.94 \pm 20.38$ & $70.80 \pm 23.17$ & 0.407 & $71.83 \pm 15.31$ & $68.90 \pm 19.77$ & 0.344 & $74.09 \pm 24.61$ & $72.08 \pm 24.80$ & 0.607 \\
\hline $\mathrm{TG}, \mathrm{mmol} / \mathrm{L}$ & $1.98 \pm 1.20$ & $1.56 \pm 1.07$ & 0.003 & $1.95 \pm 1.34$ & $1.83 \pm 1.24$ & 0.599 & $2.33 \pm 0.72$ & $1.35 \pm 0.86$ & 0.893 \\
\hline $\mathrm{TC}, \mathrm{mmol} / \mathrm{L}$ & $5.37 \pm 1.40$ & $4.58 \pm 1.29$ & $<0.001$ & $5.42 \pm 0.80$ & $5.60 \pm 0.88$ & 0.254 & $4.09 \pm 1.21$ & $3.93 \pm 1.46$ & 0.002 \\
\hline $\mathrm{HDL}, \mathrm{mmol} / \mathrm{L}$ & $1.25 \pm 0.29$ & $1.25 \pm 0.36$ & 0.891 & $1.19 \pm 0.21$ & $1.21 \pm 0.22$ & 0.654 & $1.31 \pm 0.34$ & $1.29 \pm 0.41$ & 0.706 \\
\hline $\mathrm{LDL}, \mathrm{mmol} / \mathrm{L}$ & $3.28 \pm 0.68$ & $2.91 \pm 0.68$ & $<0.001$ & $3.44 \pm 0.59$ & $3.32 \pm 0.49$ & 0.025 & $3.11 \pm 0.77$ & $3.09 \pm 0.59$ & 0.863 \\
\hline TBIL, umol/L & $12.83 \pm 4.62$ & $13.56 \pm 5.18$ & 0.209 & $12.79 \pm 4.36$ & $14.06 \pm 5.31$ & 0.180 & $12.87 \pm 4.90$ & $13.16 \pm 4.98$ & 0.708 \\
\hline $\mathrm{FPG}, \mathrm{mmol} / \mathrm{L}$ & $5.20 \pm 1.70$ & $4.91 \pm 1.12$ & 0.107 & $5.75 \pm 2.14$ & $5.30 \pm 1.22$ & 0.115 & $4.64 \pm 0.71$ & $4.65 \pm 0.95$ & 0.887 \\
\hline
\end{tabular}

Abbreviations: BMI body mass index, ALT alanine aminotransferase, AST aspartate aminotransferase, GGT $\gamma$-glutamyltransferase, ALP alkaline phosphatase, TG triglyceride, $T C$ total cholesterol, $H D L$ high-density lipoprotein, $L D L$ low-density lipoprotein, $T B I L$ total bilirubin, FPG fasting plasma glucose, NAFLD nonalcoholic fatty liver disease

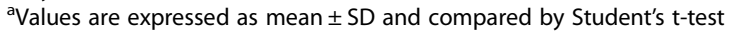

in the overall series, higher LDL level in NAFLD patients and higher TC level in healthy controls. Similar, rs2954029 A carriers possess the higher serum levels of GGT and LDL in the overall series and higher TC levels in healthy controls, the results above-mentioned were consist with the previous studies which conducted in other countries.
There are some limitations of our study that must be acknowledged, 1) the lacking of liver biopsy is the main limitation of our study, however, liver biopsy is invasive, which may lead to a small risk of serious morbidity. Thereby, we used abdominal ultrasound to diagnose NAFLD in the present study; 2) all the included subjects in this study are Han nationality, our conclusion may

Table 6 Clinical Characteristics of TRIB1 rs2954029 A Carriers and Non-Carriers in the Study Population ${ }^{\text {a }}$

\begin{tabular}{|c|c|c|c|c|c|c|c|c|c|}
\hline \multirow[t]{2}{*}{ Characteristic } & \multicolumn{3}{|l|}{ Overall Series } & \multicolumn{3}{|c|}{ NAFLD Patients } & \multicolumn{3}{|l|}{ Controls } \\
\hline & $\begin{array}{l}\text { Carriers } \\
(n=212)\end{array}$ & $\begin{array}{l}\text { Non-Carriers } \\
(n=109)\end{array}$ & $P$ Value & $\begin{array}{l}\text { Carriers } \\
(n=106)\end{array}$ & $\begin{array}{l}\text { Non-Carriers } \\
(n=40)\end{array}$ & P Value & $\begin{array}{l}\text { Carriers } \\
(n=106)\end{array}$ & $\begin{array}{l}\text { Non-Carriers } \\
(n=69)\end{array}$ & $P$ Value \\
\hline Female, \% & $97(45.8)$ & $55(50.5)$ & 0.424 & $44(41.5)$ & $21(52.5)$ & 0.233 & $53(50)$ & $34(49.3)$ & 0.925 \\
\hline Age, y & $60.70 \pm 13.79$ & $60.08 \pm 13.84$ & 0.704 & $60.94 \pm 15.60$ & $61.39 \pm 16.10$ & 0.874 & $60.48 \pm 11.90$ & $59.64 \pm 12.11$ & 0.650 \\
\hline BMI, kg/m² & $24.53 \pm 4.29$ & $24.26 \pm 3.48$ & 0.566 & $27.01 \pm 4.22$ & $26.74 \pm 2.84$ & 0.696 & $22.19 \pm 2.79$ & $22.83 \pm 2.99$ & 0.157 \\
\hline $\mathrm{ALT}, \mathrm{U} / \mathrm{L}$ & $26.71 \pm 21.78$ & $23.97 \pm 15.29$ & 0.243 & $29.82 \pm 17.00$ & $30.23 \pm 19.41$ & 0.900 & $23.77 \pm 25.21$ & $19.82 \pm 9.90$ & 0.217 \\
\hline AST, U/L & $23.68 \pm 11.74$ & $23.23 \pm 10.92$ & 0.738 & $24.12 \pm 8.60$ & $24.46 \pm 10.02$ & 0.836 & $23.27 \pm 14.11$ & $22.28 \pm 11.24$ & 0.623 \\
\hline GGT, U/L & $36.53 \pm 37.60$ & $29.64 \pm 20.11$ & 0.035 & $41.06 \pm 27.28$ & $36.08 \pm 24.46$ & 0.304 & $32.26 \pm 44.95$ & $25.42 \pm 15.25$ & 0.151 \\
\hline$A L P, U / L$ & $73.09 \pm 20.44$ & $71.19 \pm 23.03$ & 0.452 & $71.59 \pm 15.08$ & $69.60 \pm 20.09$ & 0.516 & $74.51 \pm 24.43$ & $72.58 \pm 24.46$ & 0.611 \\
\hline $\mathrm{TG}, \mathrm{mmol} / \mathrm{L}$ & $1.65 \pm 1.17$ & $1.49 \pm 0.91$ & 0.233 & $1.95 \pm 1.35$ & $1.83 \pm 1.21$ & 0.609 & $1.36 \pm 0.87$ & $1.28 \pm 0.54$ & 0.515 \\
\hline $\mathrm{TC}, \mathrm{mmol} / \mathrm{L}$ & $4.71 \pm 1.39$ & $4.94 \pm 1.78$ & 0.142 & $5.44 \pm 0.82$ & $5.54 \pm 0.84$ & 0.535 & $4.57 \pm 1.20$ & $4.03 \pm 1.47$ & 0.008 \\
\hline $\mathrm{HDL}, \mathrm{mmol} / \mathrm{L}$ & $1.26 \pm 0.29$ & $1.25 \pm 0.35$ & 0.721 & $1.20 \pm 0.20$ & $1.19 \pm 0.24$ & 0.923 & $1.32 \pm 0.34$ & $1.27 \pm 0.40$ & 0.376 \\
\hline $\mathrm{LDL}, \mathrm{mmol} / \mathrm{L}$ & $3.17 \pm 0.65$ & $2.94 \pm 0.72$ & 0.003 & $3.23 \pm 0.51$ & $2.88 \pm 0.54$ & 0.056 & $3.12 \pm 0.76$ & $3.08 \pm 0.59$ & 0.705 \\
\hline TBIL, umol/L & $12.90 \pm 4.67$ & $13.55 \pm 5.47$ & 0.268 & $12.72 \pm 4.39$ & $14.16 \pm 5.18$ & 0.092 & $13.06 \pm 4.94$ & $13.20 \pm 5.56$ & 0.860 \\
\hline FPG, mmol/L & $5.16 \pm 1.67$ & $4.94 \pm 1.18$ & 0.225 & $5.74 \pm 2.12$ & $5.35 \pm 1.37$ & 0.272 & $4.61 \pm 0.77$ & $4.67 \pm 0.94$ & 0.656 \\
\hline
\end{tabular}

Abbreviations: BMI body mass index, $A L T$ alanine aminotransferase, $A S T$ aspartate aminotransferase, GGT $\gamma$-glutamyltransferase, $A L P$ alkaline phosphatase, $T G$ triglyceride, $T C$ total cholesterol, $H D L$ high-density lipoprotein, $L D L$ low-density lipoprotein, $T B I L$ total bilirubin, FPG fasting plasma glucose, NAFLD nonalcoholic fatty liver disease

aValues are expressed as mean \pm SD and compared by Student's t-test 
not be applicable to other nationality absolutely; 3 ) the amount of subjects were still relative small, more subjects should be included in the future study.

\section{Conclusion}

In summary, we investigated the relationship of TRIB1 rs17321515 and rs2954029 with the development of NAFLD and lipids metabolism in Chinese Han population for the first time. Our results showed that TRIB1 rs17321515 and rs2954029 were significant associated with the risk of NAFLD, and the rs17321515 A and rs2954029 A alleles affect the serum levels of multiple lipid profiles in included subjects. Further studies in larger and multiple ethnic populations are needed to confirm the present data.

\section{Abbreviations}

AASLD: American association for the study of liver diseases; ALP: Alkaline phosphatase; ALT: Alanine aminotransferase; AST: Aspartate aminotransferase; BMI: Body mass index; Cl: Confidence intervals; CVD: Cardiovascular disease; EDTA: Ethylene diamine tetraacetic acid; FPG: Fasting plasma glucose; GGT: Gamma-glutamyltranspeptidase; GWAS: Genome-wide association studies; HCC: Hepatocellular carcinoma; HDL: High density lipoprotein; LDL: Low density lipoprotein; NAFL: Non-alcoholic fatty liver; NAFLD: Nonalcoholic fatty liver disease; NASH: Non-alcoholic steatohepatitis; ORs: Odds ratios; PCR: Polymerase chain reaction; SNP: Single nucleotide polymorphism; TC: Total cholesterol; TG: Triglycerides; TRIB1: Tribbles-1

\section{Acknowledgements}

We would like to thank the department of Gastroenterology for the recruitment of subjects.

\section{Funding}

This study was supported by Grants of National Natural Science Foundation of China (31770837) and the Qingdao People's Livelihood Science and technology plan (18-6-1-68-nsh).

\section{Availability of data and materials}

None.

\section{Authors' contributions}

Study concept and design: LQ, XYN, and XSY. Subjects collection: LQ, XF, MJ, LSS, CLZ, GH, GN, and JWW. Acquisition and analysis of data: LQ, XF, MJ, LSS, and CLZ. The drafting and writing of the manuscript: LQ. The revision of the manuscript: XF, XYN and XSY. All authors approved the final manuscript.

\section{Ethics approval and consent to participate}

The study protocol was approved by the Ethics Committee of Qingdao Municipal Hospital before participation (Approval NO.2017-20). All the subjects have signed written informed consent.

\section{Consent for publication}

Not applicable.

\section{Competing interests}

The authors declare that they have no competing interests.

\section{Publisher's Note}

Springer Nature remains neutral with regard to jurisdictional claims in published maps and institutional affiliations.

\section{Author details}

${ }^{1}$ Medical College of Qingdao University, Qingdao 266071, China. ${ }^{2}$ Department of Infectious Disease, Qingdao Municipal Hospital, Qingdao 266011, China. ${ }^{3}$ Department of Gastroenterology, Qingdao Municipal Hospital, 1 Jiaozhou Road, Qingdao 266011, Shandong Province, China.
${ }^{4}$ Central Laboratories, Qingdao Municipal Hospital, Qingdao 266071, China. ${ }^{5}$ Digestive Disease Key Laboratory of Qingdao, Qingdao 266071, China.

Received: 23 December 2018 Accepted: 26 February 2019 Published online: 09 March 2019

\section{References}

1. Danford CJ, Yao ZM, Jiang ZG. Non-alcoholic fatty liver disease: a narrative review of genetics. J Biomed Res. 2018;32:389-400.

2. Younossi $Z M$, Koenig $A B$, Abdelatif D, Fazel Y, Henry L, Wymer M. Global epidemiology of nonalcoholic fatty liver disease-meta-analytic assessment of prevalence, incidence, and outcomes. Hepatology. 2016;64:73-84.

3. Fiorucci S, Biagioli M, Distrutti E. Future trends in the treatment of nonalcoholic steatohepatitis. Pharmacol Res. 2018;134:289-98.

4. Younossi ZM, Stepanova M, Negro F, Hallaji S, Younossi Y, Lam B, Srishord M. Nonalcoholic fatty liver disease in lean individuals in the United States. Medicine (Baltimore). 2012;91:319-27.

5. M Younossi Z. Patient-reported Outcomes and the Economic Effects of Non-Alcoholic Fatty Liver Disease and Non-alcoholic Steatohepatitis - The Value Proposition; 2018.

6. Liangpunsakul S, Chalasani N. Lipid mediators of liver injury in nonalcoholic fatty liver disease. Am J Physiol Gastrointest Liver Physiol. 2019;316:G75-81.

7. Feng S, Dai Z, Liu AB, Huang J, Narsipur N, Guo G, Kong B, Reuhl K, Lu W, Luo Z, Yang CS. Intake of stigmasterol and beta-sitosterol alters lipid metabolism and alleviates NAFLD in mice fed a high-fat western-style diet. Biochim Biophys Acta Mol Cell Biol Lipids. 2018;1863:1274-84.

8. Anstee QM, Day CP. The genetics of NAFLD. Nat Rev Gastroenterol Hepatol. 2013;10:645-55.

9. Krishan S, Jain D, Bathina Y, Kale A, Saraf N, Saigal S, Choudhary N, Baijal SS, Soin A. Non-invasive quantification of hepatic steatosis in living, related liver donors using dual-echo Dixon imaging and single-voxel proton spectroscopy. Clin Radiol. 2016;71:58-63.

10. Zhang Q, Zhang HM, Qi WQ, Zhang YG, Zhao P, Jiao J, Wang JB, Zhang CY. 3.0T (1) H magnetic resonance spectroscopy for assessment of steatosis in patients with chronic hepatitis C. World J Gastroenterol. 2015;21:6736-44.

11. Leon-Mimila P, Vega-Badillo J, Gutierrez-Vidal R, Villamil-Ramirez H, VillarealMolina T, Larrieta-Carrasco E, Lopez-Contreras BE, Kauffer LR, MaldonadoPintado DG, Mendez-Sanchez N, et al. A genetic risk score is associated with hepatic triglyceride content and non-alcoholic steatohepatitis in Mexicans with morbid obesity. Exp Mol Pathol. 2015;98:178-83.

12. Wilkin F, Suarez-Huerta N, Robaye B, Peetermans J, Libert F, Dumont JE, Maenhaut $C$. Characterization of a phosphoprotein whose mRNA is regulated by the mitogenic pathways in dog thyroid cells. Eur J Biochem. 1997:248:660-8.

13. Lohan F, Keeshan K. The functionally diverse roles of tribbles. Biochem Soc Trans. 2013;41:1096-100.

14. Kathiresan S, Melander O, Guiducci C, Surti A, Burtt NP, Rieder MJ, Cooper GM, Roos C, Voight BF, Havulinna AS, et al. Six new loci associated with blood low-density lipoprotein cholesterol, high-density lipoprotein cholesterol or triglycerides in humans. Nat Genet. 2008;40:189-97.

15. Willer CJ, Sanna S, Jackson AU, Scuteri A, Bonnycastle LL, Clarke R, Heath SC, Timpson NJ, Najjar SS, Stringham HM, et al. Newly identified loci that influence lipid concentrations and risk of coronary artery disease. Nat Genet. 2008:40:161-9.

16. Tai ES, Sim XL, Ong TH, Wong TY, Saw SM, Aung T, Kathiresan S, Orho-Melander M, Ordovas JM, Tan JT, Seielstad M. Polymorphisms at newly identified lipidassociated loci are associated with blood lipids and cardiovascular disease in an Asian Malay population. J Lipid Res. 2009:50:514-20.

17. Wang L, Jing J, Fu Q, Tang $X$, Su L, Wu S, Li G, Zhou L. Association study of genetic variants at newly identified lipid gene TRIB1 with coronary heart disease in Chinese Han population. Lipids Health Dis. 2015;14:46.

18. Varbo A, Benn M, Tybjaerg-Hansen A, Grande P, Nordestgaard BG. TRIB1 and GCKR polymorphisms, lipid levels, and risk of ischemic heart disease in the general population. Arterioscler Thromb Vasc Biol. 2011;31:451-7.

19. Ikeoka T, Hayashida N, Nakazato M, Sekita T, Murata-Mori F, Ando T, Abiru N, Yamasaki H, Kudo T, Maeda T, et al. The a>T polymorphism of the tribbles homolog 1 gene is associated with serum triglyceride concentrations in Japanese community-dwelling women. Tohoku J Exp Med. 2014;233:149-53.

20. Ampuero J, Gallego-Duran R, Romero-Gomez M. Association of NAFLD with subclinical atherosclerosis and coronary-artery disease: meta-analysis. Rev Esp Enferm Dig. 2015;107:10-6. 
21. Li XL, Sui JQ, Lu LL, Zhang NN, Xu X, Dong QY, Xin YN, Xuan SY. Gene polymorphisms associated with non-alcoholic fatty liver disease and coronary artery disease: a concise review. Lipids Health Dis. 2016;15:53.

22. Engin A. Non-alcoholic fatty liver disease. Adv Exp Med Biol. 2017:960:443-67.

23. Rickham PP. Human experimentation. Code of ethics of the world medical association. Declaration of Helsinki. Br Med J. 1964;2:177.

24. Fan JG, Jia JD, Li YM, Wang BY, Lu LG, Shi JP, Chan LY. Chinese Association for the Study of liver D: guidelines for the diagnosis and management of nonalcoholic fatty liver disease: update 2010: (published in Chinese on Chinese journal of hepatology 2010; 18:163-166). J Dig Dis. 2011;12:38-44.

25. Younes R, Bugianesi E. Should we undertake surveillance for HCC in patients with NAFLD? J Hepatol. 2018;68:326-34

26. Milic S, Lulic D, Stimac D. Non-alcoholic fatty liver disease and obesity: biochemical, metabolic and clinical presentations. World J Gastroenterol. 2014;20:9330-7.

27. Fan JG, Kim SU, Wong WW. New trends on obesity and NAFLD in Asia. J Hepatol. 2017;67:862-73.

28. Friedman SL, Neuschwander-Tetri BA, Rinella M, Sanyal AJ. Mechanisms of NAFLD development and therapeutic strategies. Nat Med. 2018;24:908-22.

29. Li YY. Genetic and epigenetic variants influencing the development of nonalcoholic fatty liver disease. World I Gastroenterol. 2012;18:6546-51.

30. Eslam M, Valenti L, Romeo S. Genetics and epigenetics of NAFLD and NASH: clinical impact. J Hepatol. 2018;68:268-79.

31. Hegedus Z, Czibula A, Kiss-Toth E. Tribbles: a family of kinase-like proteins with potent signalling regulatory function. Cell Signal. 2007;19:238-50.

32. Burkhardt R, Toh SA, Lagor WR, Birkeland A, Levin M, Li X, Robblee M, Fedorov VD, Yamamoto M, Satoh T, et al. Trib1 is a lipid- and myocardial infarction-associated gene that regulates hepatic lipogenesis and VLDL production in mice. J Clin Invest. 2010;120:4410-4.

33. Garcia-Rios A, Perez-Martinez P, Mata P, Fuentes F, Lopez-Miranda J, Alonso R, Caballero J, Mata N, Perez-Jimenez F, Ordovas JM. Polymorphism at the TRIB1 gene modulates plasma lipid levels: insight from the Spanish familial hypercholesterolemia cohort study. Nutr Metab Cardiovasc Dis. 2011;21: $957-63$

34. Varga TV, Sonestedt E, Shungin D, Koivula RW, Hallmans G, Escher SA, Barroso I, Nilsson P, Melander O, Orho-Melander M, et al. Genetic determinants of long-term changes in blood lipid concentrations: 10-year follow-up of the GLACIER study. PLoS Genet. 2014;10:e1004388.

Ready to submit your research? Choose BMC and benefit from:

- fast, convenient online submission

- thorough peer review by experienced researchers in your field

- rapid publication on acceptance

- support for research data, including large and complex data types

- gold Open Access which fosters wider collaboration and increased citations

- maximum visibility for your research: over $100 \mathrm{M}$ website views per year

At BMC, research is always in progress.

Learn more biomedcentral.com/submissions 